\title{
“Arap Baharı” Sonrası Dönemde Fırat-Dicle Uyuşmazlığı
}

\author{
Murat BAYAR* \\ Tuğba BAYAR**
}

\section{Öz}

Irak, Suriye ve Türkiye arasında $1960^{\prime}$ Iı yıllardan beri devam etmekte olan su sorunu, Fırat-Dicle havzasında artan kuraklık, nüfus ve tarım-enerji ihtiyaçlarıyla taraflara zarar veren bir çıkmaza girmiştir. Üç kıyıdaş arasında nehirlerin statüsü ve kullanımı hususlarına odaklanan uyuşmazlık bazı dönemlerde tırmanarak askeri tehditler içermiş olsa da sıcak çatışmaya dönüşmemiş ve su insan hayatını tehdit edecek şekilde bir silah olarak kullanılmamıştır. Öte yandan, Suriye ve Türkiye arasında 2000'li yıllarda yaşanan yakınlaşma döneminde dahi nihai bir anlaşma sağlanamamıştır. Bu arka plandan hareketle makalemiz "Arap Baharı" sonrası dönemde su sorunun yapısal bir dönüşümden geçmekte olduğunu vurgulamaktadır. Şöyle ki, bağımsızık ilan etmeye hazırlanan Kuzey Irak Kürtlerinin yanı sıra Daeş/IŞiD ile PYD-YPG'nin havza boyunca stratejik toprakları ve barajları ele geçirmesi, uyuşmazlığa yeni devlet ve devlet-dışı aktörlerin birincil taraf olması intimalini doğurmuştur. Ayrıca, Suriye ve Irak'taki iç savaşlarda suyun ölümcül bir silah olarak kullanılması diğer bir önemli gelişmedir. Makalemiz tarafların ve konuların artmakta olduğu su sorununda uyuşmazlık çözümü ihtimalinin artık daha azaldığı sonucuna varmaktadır.

Anahtar Kelimeler: Fırat, Dicle, Irak, Suriye, Türkiye, Daeş, IşiD.

\section{The Euphrates-Tigris Conflict in the Post "Arab Spring" Era}

\section{Abstract}

The water conflict between Iraq, Syria and Turkey that has continued since the 1960s has entered a mutually-hurting stalemate due to increasing populations, drought and agricultural-energy needs in the basin. While the conflict that centers around the status and use of rivers escalated to the level of military threats during certain periods, it has not evolved into any military conflict or the use of water in a life-threating way. Yet, a final agreement has not been reached even during the raproachement period between Syria and Turkey in the 2000s. Based on this premises, our paper underlines that the conflict has been going through a structural transformation in the "post-Arab Spring" era. The capture of some strategic lands and dams along the Euphrates-Tigris basin by Daesh/ISIS and PYD-YPG, as well as by the Northern Iraqi Kurds, who are preparing to declare independence, indicate that new state and non-state actors may become primary parties in this conflict. Furthermore, the use of water as a lethal weapon in the Iraqi and Syrian civil wars signify another important development. This paper concludes that the resolution of this conflict has become less likely due to the increasing number of parties and issues.

Keywords: Euphrates, Tigris, Iraq, Syria, Turkey, Daesh, ISIS.

* Yrd.Doç.Dr., Siyaset Bilimi ve Kamu Yönetimi, Ankara Sosyal Bilimler Üniversitesi. murat.bayar@asbu.edu.tr

** Öğr.Gör.Dr., Uluslararası Ilişkiler, Bilkent Üniversitesi. tugba.bayar@bilkent.edu.tr 


\section{GíRiş}

Irak, Suriye ve Türkiye arasında 1960'lı yıllardan beri devam etmekte olan, Fırat-Dicle nehirlerinin hukuki statüleri ve kullanımı hususlarının öne çıktığı su sorununda gerilim bazı dönemlerde trrmanmış, ancak sıcak çatışma gerek birincil tarafların inisiyatifi, gerekse üçüncü tarafların girişimleriyle önlenmiştir. ${ }^{1}$ Buna karşın, artan kuraklık, nüfus ve enerji intiyacı gibi sebeplerden dolayı uyuşmazlık taraflara çeşitli derecelerde zarar veren bir çıkmaza girmiştir. Bu arka planı dikkate alarak makalemiz, su sorununun "Arap Baharı" sonrası dönemde geçirmekte olduğu yapısal değişimi uyuşmazlık çözümü perspektifinden incelemektedir.

2010 yılında Tunus'ta başlayıp Libya ile Mısır başta olmak üzere birçok Ortadoğu ülkesine yayılan ve demokratikleşmeye yönelik halk ayaklanmalarını içeren döneme "Arap Baharı" tanımlaması yapılmaktadır. Bu tanımdan hareketle, eski rejimin askeri darbeyle geri dönüş yaptı̆̆ı Mısır, Kaddafi sonrası iç çatışmalara sürüklenen Libya ve özellikle iç savaşların en kanlı şekilde sürdüğü Suriye ile Yemen vakaları göz önüne alındığında sözde baharın 2017 yılı itibariyle sona erdiği ve Ortadoğu’nun "Arap Baharı" sonrası döneme girdiğinden söz edilebilir. Bu dönemde bölgeyi çalışan akademisyenlerin ve uzmanların üzerinde en fazla mesai harcadıkları konular, doğal olarak, terörizm ve iç savaş olmakla birlikte, günlük siyasetin üstünde bir konu olarak kabul edilebilecek su sorununun takip edilmesi önem arz etmektedir.

Aşağıda öncelikle su sorununun tarihi arka planı ve uluslararası hukuktaki yeri ele alınmaktadır. Daha sonra bu noktalardan hareketle uyuşmazlığın "Arap Baharı" sonrası dönemde geçirmekte olduğu yapısal değişimin sebepleri ortaya konulmaktadır. Sonuç bölümünde, belirtilen değişimin uyuşmazlığın çözüm olasılığını nasıl etkilediği tartışımaktadır.

\section{SU SORUNUNUN ARKA PLANI}

Artan nüfus ve enerji ihtiyacının yanı sıra kuraklık sebepleriyle dünyada suya yönelik arz-talep dengesizliği oluşmaktadır. ${ }^{2}$ Birleşmiş Milletler Gıda ve Tarım Organizasyonu 2015'de yayınladığı bir raporunda dünya nüfusunun 9-10 milyar kişi seviyesine yükselmesinin beklendiği 2050 yılında tatlı su kaynakları açısından en fazla sıkınt yaşanacak bölgelerin başında Ortadoğu ve Kuzey Afrika'yı göstermektedir. ${ }^{3}$ Bu bağlamda, tarih boyunca olduğu gibi bugün ve gelecekte de Fırat ve Dicle nehirleri Ortadoğu toplumları için yaşamsal öneme sahip olmaya devam etmektedir.

Yukarıda belirtilen arz-talep dengesizliğine siyasi istikrasızlıklar ve uluslararası sistemin anarşik yapısı eklendiğinde su savaşlarının ortaya çıkacağı tahmininde bulunan uzmanlar her şeyden önce sorunun kritikliğine dikkat çekmişlerdir. ${ }^{4}$ Ayrıca, Irak ve Suriye'de 2010'la-

1 Kıyıdaş ülkeler alfabetik olarak sıralanmıştır.

2 S. Yoffe, et al., 'Geography of International Water Conflict and Cooperation: Data Sets and Applications', Water Resources Research, c. 40, 2004, s. 1-12.

3 Birleşmiş Milletler Gıda ve Tarım Organizasyonu, Towards a Water and Food Secure Future: Critical Perspectives for Policy-makers, Roma, Marsilya: World Water Council, 2015.

4 T.F. Homer-Dixon, 'On the Threshold: Environmental Changes as Causes of Acute Conflict', International Security, c. 16, sy. 2, 1991, s. 76-116. M. O'Hanlon, 'Coming Conflicts: Interstate War in the New Millenium', Harvard International Review, 2001, Yaz, s. 42-46. Z. Akbaş, 'Türkiye'nin Fırat ve Dicle Sınıraşan Sularından Kaynaklanan Güvenlik Sorunu ve Çatışma Riski', Bilig, c. Kış, sy. 72, 2015, s. 93-116. 
rın başında yaşanan kuraklığın ve tarımsal üretimdeki çöküşün yol açtığı iç göçlerin bu ülkelerde toplu ayaklanmalara, silahlı örgütlerin kolaylıkla militan devşirmesine, dolayısıyla yeni askeri müdahalelere yol açt̆ğı ileri sürülmektedir. ${ }^{5}$ Büyük resme bakıldığında, Ortadoğu'daki uyuşmazlıklarda kaynak kıtlığının (veya petrolde olduğu gibi, fazlalığının) yanı sıra siyasi kurumların yeterince gelişememiş olması, mezhepsel düşmanlıklar, temsiliyet eksikliği gibi birçok temel sorunun rol oynadığını dikkate almak gerekmektedir. ${ }^{6}$

Her ikisi de Türkiye topraklarında doğan nehirlerden 2,786 km uzunluğundaki Fırat Suriye'den geçip Irak'ta Dicle ile birleşerek Şattülarap'ı oluşturduktan sonra Basra Körfezi'ne akmaktadır. Fırat nehrinin 1930-1973 döneminde yıllık ortalama su kapasitesi yaklaşık 30 milyar metreküpken bu miktar 1974-2010 döneminde 25 milyar metreküp civarına düşmüştür. Yıllık kapasitesi yaklaşık 54,7 milyar metreküp olan Dicle nehri ise 1,800 km uzunlukta olup Suriye sınırını takip ederek Türkiye'den çıktıktan sonra Irak'tan sona ermektedir. ${ }^{7}$

Şekil 1: Fırat-Dicle Havzası

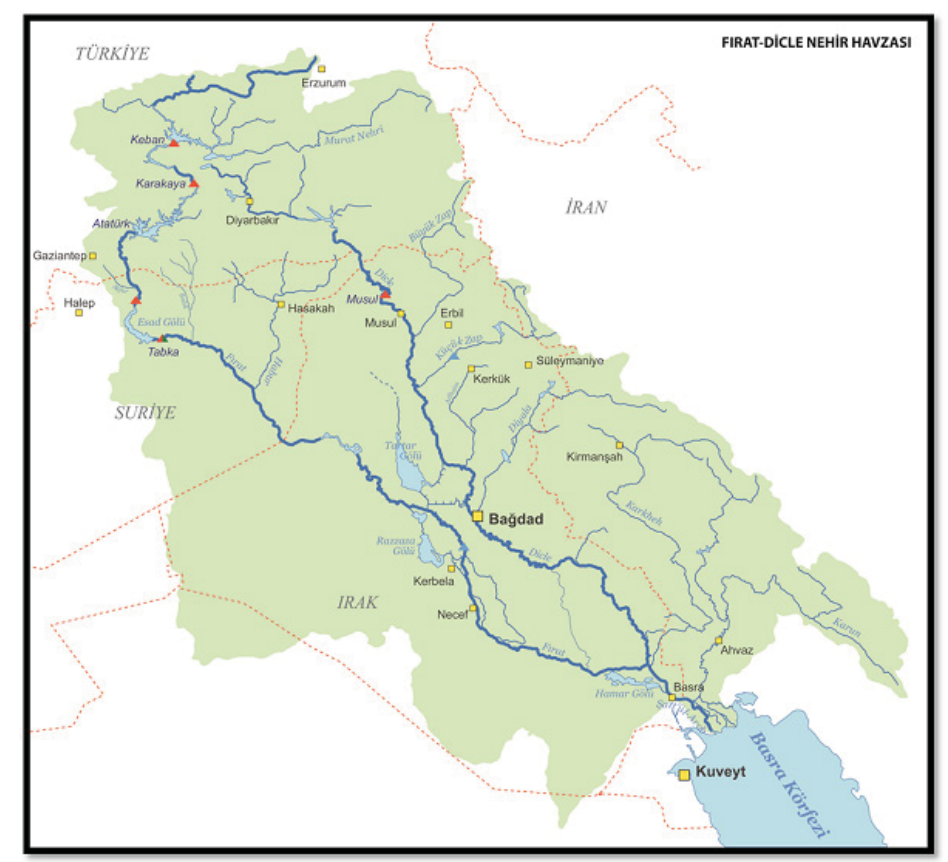

Kaynak: T.C. Orman ve Su İşleri Bakanlığı, Su Yönetimi Genel Müdürlügüü, 2015. ${ }^{8}$

5 M. Al Jabbari, et al., 'Rivers of Babylon: Iraq's Water Crisis - And What Turkey Should Do', Foreign Affairs, 23 August 2015.

6 C. Yenigün, 'Conflict Resolution for the Middle East: Sectarian Rapprochement', Türkiye Ortadoğu Çalışmaları Dergisi, c. 3, sy. 2, 2016, s. 13-27.

7 United Nations Economic and Social Commission for Western Asia, Inventory of Shared Water Resources in Western Asia, New York: United Nations, 2013. D.D. Kırkıcı, 'Sınıraşan Sular Bağlamında Türkiye, Suriye ve Irak İlişkileri', Uzmanlık Tezi, T.C. Orman ve Su İşleri Bakanlığı, Ankara 2014, http://suyonetimi.ormansu.gov.tr/Libraries/su/DUYGU_DO\%C4\%9EU_KIRKICI-UZMANLIK_ TEZ\%C4\%BO__nihai.sflb.ashx, (erişim 4 Haziran 2017).

8 'Su Hukuku ve Politikaları İhtisas Heyeti “Dicle-Fırat Havzası” Gündemi İle Toplandı', T.C. Orman ve Su İşleri Bakanlığı, Su Yönetimi Genel Müdürlüğü, 17 Aralık 2015, http://suyonetimi.ormansu. gov.tr/AnaSayfa/resimliHaber/15-12-17/Su_Hukuku_ve_Politikalar\%C4\%B1_\%C4\%BOhtisas Heyeti_\%E2\%80\%9CDicle-F\%C4\%B1rat_Havzas\%C4\%B1\%E2\%80\%9D_G\%C3\%BCndemi_\%C4\%B Ole Topland\%C4\%B1.aspx?sflang=tr, (erişim 4 Haziran 2017). 
Güncel veriler iç savaş halindeki aşağı kıyıdaşlardan temin edilememekle birlikte, geçmişteki rakamlardan hareketle 2020 yılı için tahmin edilen kişi başına düşen yıllık su miktarı Irak, Suriye ve Türkiye'de, sırasıyla, 950 m3, 780 m3 ve 980 m3 şeklindedir. Bu miktarlar "su zengini" olarak tanımlanan ülkelerin alt sınırıyla $(8,000 \mathrm{~m} 3)$ karşılaştırıldığında dahi Ortadoğu'daki su kaynaklarının kıtlığı ortaya çıkmaktadır. ${ }^{9}$

Fırat ve Dicle nehirleri üzerinde yapılan barajların en büyükleri arasında Atatürk, Keban ve Karakaya (Türkiye), Tabka (Suriye) ve Musul (Irak) bulunmaktadır (Şekil 1). Irak, Suriye ve Türkiye arasındaki su sorunu bu barajların inşa edilme süreciyle başlamıştı. Fırat nehri üzerinde 1960 'ların sonlarında yapımına başlanan barajlardan Tabka 1973'de ve Keban 1975 'de tamamlanmıştr. Bu iki barajın yapımında Sovyet Sosyalist Cumhuriyetler Birliği (SSCB) Suriye'ye teknik destek verirken Amerika Birleşik Devletleri Türkiye'ye 40 milyon dolar kredi sağlamıştı. ${ }^{10}$

Tabka ve Keban barajlarının faaliyete geçmesinin hemen akabinde Irak aşağı kıyıdaş olarak su miktarının düştüğü şikâyetinde bulunmuş ve Suriye ile askeri çatışmanın eşiğine gelmiştir. ${ }^{11} 2009$ yılında ise Irak dörtte bir seviyesine kadar inen su miktarından Türkiye'nin Fırat üzerindeki barajlarını sorumlu tutup yukarı kıyıdaşından daha fazla su talep etmiş, ancak artıılan su akışını yeterli bulmamıştır. ${ }^{12}$ Egemenlik hakkı ve suyun miktarı ile kalitesi hususlarının öne çıktığı bu uyuşmazlıkta yukarı kıyıdaş Türkiye, Fırat ve Dicle nehirlerinin tek bir havza oluşturduğunu ve "hakça, akılcı ve optimum" kullanım çerçevesinde aşağı kıyıdaşlara "ciddi zarar" vermeme yaklaşımını benimsediğini vurgulamaktadır. ${ }^{13}$ Suriye ise Lübnan'dan sonra kendisinin yukarı kıyıdaş ve Türkiye'nin aşağı kıyıdaş olduğu 404 km uzunluğundaki Asi nehrinin son bulduğu Hatay'ın Türkiye'ye ait olduğunu resmen kabul etmediğinden Fırat-Dicle ile Asi nehirlerinde kendisinin uyguladığı farklı politikaları tutarsız görmemektedir. ${ }^{14}$

Su sorununa taraf ülkeler arasında varılmış kritik mutabakatlar: 1975 krizinden sonra Suudi Arabistan'ın arabuluculuğuyla suyun \%58 Irak ve \%42 Suriye şeklinde bölüşülmesi; ${ }^{15}$ 1987 'de Türkiye'nin 500 m3/sn. suyu Suriye sınırından bırakması yönünde iki ülkenin protokol imzalaması; 1998 Adana Mutabakat ile Suriye'nin PKK'yı ülke dışına çıkarma-

9 'Water Issues between Turkey, Syria and Iraq', Stratejik Araştırmalar Merkezi (SAM), 2012, http://sam. gov.tr/wp-content/uploads/2012/01/WATER-ISSUES-BETWEEN-TURKEY-SYRIA-AND-IRAQ.pdf, (erişim 6 Haziran 2017). 'Toprak Su Kaynakları', 2014, http://www.dsi.gov.tr/toprak-ve-su-kaynaklari, (erişim 7 Haziran 2017).

10 'International Water Event Database, International Freshwater Treaties Database', 12.05.2017, The Transboundary Freshwater Dispute Database, College of Earth, Ocean, and Atmospheric Sciences,

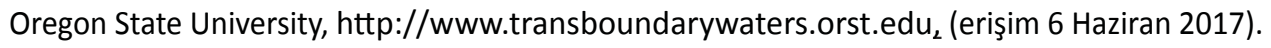

11 A. Kıran, Ortadogu'da Su: Bir Çatışma ya da Uzlaşma Alanı, Istanbul: Kitap Yayınevi 2005. 'Dikkatle Ele Alınız! Tabka Barajı Trajedisi', ORSAM, 2017, http://orsam.org.tr/orsam/DPAnaliz/12740, (erişim 4 Haziran 2017).

12 J.P. Jongerden, 'Dams and Politics in Turkey: Utilizing Water, Developing Conflict', Middle East Policy, c. 17, sy. 1, 2010, s. 137 - 143.

13 'Türkiye'nin Su Politikas', T.C. Dışişleri Bakanlı̆̆ı, 2017, http://www.mfa.gov.tr/turkiye nin-su-politikasi. tr.mfa, (erişim 4 Haziran 2017).

14 United Nations, Inventory of Shared Water Resources in Western Asia, 2013. C. Zehir, Ortadoğu'da Su Medeniyetlerinden Su Savaşlarına, Istanbul: Su Vakfi 2003. A. Kibaroğlu, et al., A Comprehensive Look to the Water Resource Policies of Turkey. TMMOB Su Politikaları Kongresi sunumu, Ankara, 2006.

151990 yııında Türkiye'nin Atatürk Barajı́nı doldurmak için tarafları önceden bilgilendirerek Fırat'ın suyunu 1 ay süreyle kesmesini müteakip Irak ve Suriye nihai bir anlaşma yapılana kadar geçerli olmak üzere bölüşüm anlaşmalarını yenilemişlerdir. 
yı kabulü; 2001 yılında Suriye ve Türkiye'nin ilgili alanlarda eğitim, teknoloji paylaşımı ve birlikte proje geliştirme yönünde ortak açıklaması ve 2002 'de protokol imzalamaları şeklindedir. Ayrıca, Irak ve Türkiye, Suriye-Türkiye sınırından 500 m3/sn. su bırakılması hususunda 2005 yılında karşılıklı anlaşmaya varmışlardır. ${ }^{16}$

Türkiye her iki nehirde hem Suriye, hem Irak açısından üst kıyıdaş konumunda bulunduğundan, uyuşmazlığın analizinde Güneydoğu Anadolu Projesi'ne (GAP) özel bir yer ayrılması gerekmektedir. Fırat-Dicle havzasında dokuz ili kapsayan bir bölgesel kalkınma projesi olan GAP'ın çerçevesi 1977 yılında oluşturulmuş ve 1989 yılında kabul edilen ana planında 22 baraj ve 19 hidroelektrik santrali (HES) öngörülmüştür. Türkiye 1975 yılında Dünya Bankası'na yaptığı destek başvurusu aşağı kıyıdaşların rızaları olmadığı için reddedilince projenin finansman yükünü büyük ölçüde tek başına üstlenmiştir. ${ }^{17}$ Bununla birlikte, Suriye ve Türkiye arasındaki 1987 protokolünde belirtilen 500 m3/sn. su akışının Dünya Bankası'nın incelemesinde adil bir miktar olarak ortaya konulduğu not edilmelidir. ${ }^{18}$ Aşağı kıyıdaşların vetosu sonucu yeterli dış kredi alınamamasının Türkiye üzerinde yaratthğı mali yükün 1980'li ve 1990'lı yıllardaki yüksek enflasyonun en önemli sebeplerinden birisi olduğunun alt çizilmektedir. ${ }^{19}$ Barajların proje durumuna Tablo 1'de yer verilmektedir.

\section{Tablo 1: GAP Barajlarının Proje Durumu}

\begin{tabular}{|c|c|c|c|}
\hline \multicolumn{2}{|l|}{ Fırat Nehri } & \multicolumn{2}{|l|}{ Dicle Nehri } \\
\hline Baraj & Proje Durumu & Baraj & Proje Durumu \\
\hline Karakaya & İşletme & Kralkızı & İşletme \\
\hline Atatürk & İşletme & Dicle & İşletme \\
\hline Çamgazi & İşletme & Batman & İşletme \\
\hline Kayacık & İşletme & Garzan & İşletme \\
\hline Birecik & İşletme & Silvan & İnşaat \\
\hline Karkamış & İşletme & Ilısu & İnşaat \\
\hline Sırımtaş & İşletme & Cizre & Proje \\
\hline Hancağız & İşletme & & \\
\hline Ardıl & İnşaat & & \\
\hline Gömikan & Proje & & \\
\hline Koçali & Proje & & \\
\hline Büyükçay & Proje & & \\
\hline Besni & Proje & & \\
\hline Bayramlı (regülatör) & Proje & & \\
\hline Kemlim & Planlama & & \\
\hline
\end{tabular}

Kaynak: DSi Genel Müdürlügü̈, 2015. ${ }^{20}$

16 'International Water Event Database, International Freshwater Treaties Database', 12.05.2017, Oregon State University.

17 GAP için öngörülen 32 milyar ABD doları kamu yatırım maliyetine karşın Türkiye 1994-2013 döneminde toplam 10,9 milyon ABD doları ve 66 milyon Avro hibe finansmanı ile 2 milyar ABD doları kredi sağlamıştır. 'Güneydoğu Anadolu Projesi Son Durum', 2016, http://yayin.gap.gov.tr/2015-gap-son-durum-yayin-...

18 A. Kibaroğlu ve I.H.O. Ünver, 'An Institutional Framework for Facilitating Cooperation in the EuphratesTigris River Basin', International Negotiation, c. 5, 2000, s. 311-330.

19 A. Swain, Managing Water Conflict: Asia, Africa and the Middle East, Londra, New York: Routledge 2004.x

20 'Güneydoğu Anadolu Projesi Son Durum', 2016, http://yayin.gap.gov.tr/2015-gap-son-durum-yayinef1457f5b1.html (erişim 4 Haziran 2017). 
Projede altyapının yanı sıra tarım, sanayii, sosyal, sağlık, çevre ve kültür bileşenleri bulunmaktadır. Bütçe içinde GAP’a ayrılan pay 1990-2011 döneminde en az \%4.9, en çok \%14.4 seviyelerinde olmuş ve özellikle 2008-2011 döneminde \%11,9'un altnna düşmemiştir. ${ }^{2122}$ Bu verilerden hareketle, Suriye-Türkiye ilişkilerinin en iyi olduğu dönemde GAP yatırımlarının hızlandırımış olduğu sonucu çıkarılabilir.

\section{ULUSLARARASI HUKUK AÇISINDAN SU SORUNU}

Su sorununda uluslararası alanındaki önemli metinlerden birisi 1992 yılında Helsinki'de imzaya açılarak 1996'da yürürlüğe giren ve 2017 itibariyle kırk taraf ülkeden mürekkep olan Birlemiş Milletler (BM) Uluslararası Göller ve Sınıraşan Su Yollarının Korunması ve Kullanılması Hakkında Sözleşmedir (kısaca, 1992 Helsinki Sözleşmesi). İmzacı ülkelerin haricinde Avrupa Birliği $(A B)$ de imzacı uluslararası örgüt olarak yer almaktadır. Türkiye'nin imzacı taraf olmadığı 1992 Helsinki Sözleşmesi, su yolları hususu hariç olacak şekilde sınıraşan suların genel prensiplerini ortaya koymaktadır. En önemli özelliği yukarı kıyıdaş ülkelerin aşağı kıyıdaşlarına "önemli zarar vermeme" yükümlülüğü getirmesi ve önemli zarar doğması halinde ne tür tazminatların gündeme gelebileceğini tartışmasıdır. ${ }^{23}$

1992 Helsinki Sözleşmesi uluslararası silahlı çatışmalar hukukuna da atflarda bulunmaktadır. 1949 tarihli Cenevre Sözleşmeleri ${ }^{24}$ ve 1977 tarihli ek protokollerine ${ }^{25}$ göre içme suyu tesisleri, depoları ve sulama kanalları gibi sivil halkın yaşamını sürdürmesi için elzem mal ve kaynaklara saldırmak yasaklanmıştır. Buna sulama şebekeleri de dahil edilmiştir. 1949 Cenevre Sözleşmesine taraf olmuş tüm ülkeler bu koşullar ile bağlanmaya rıza göstermişlerdir. Türkiye de Cenevre konvansiyonuna taraf bir ülkedir, ancak ek protokolleri kabul etmemiştir. Suriye ve Irak ise Ek Protokol 1'i kabul etmiş ancak Ek Protokol 2'yi kabul etmemiştir. ${ }^{26}$

Diğer bir önemli metin olan Uluslararası Su Yollarının Ulaşım Dışı Amaçlarla Kullanımı Sözleşmesi 1997 yılında BM Genel Kurulu'nda 3 ret ve 27 çekimsere karşı 103 oy ile kabul edilmiştir. Çin ve Burundi'nin yanı sıra Türkiye ret oyu veren üç ülke arasında yer alırken Irak ve Suriye Sözleşmeye resmen katılmışlardır. ${ }^{27}$ BM Türkiye Daimî Temsilcisi Büyükelçi Hüseyin Çelem bir çerçeve anlaşması olması sıfatiyla bu sözleşmenin genel prensipleri yansıtması gerektiğini, söz konusu metnin bir çerçeve oluşturmak yerine planlanmış bir takım tedbirleri yansıttı̆ını, böyle bir uygulamanın uluslararası hukukta

21 'GAP Sunum”, “GAP'ta Son Durum', GAP Bölge Kalkınma İdaresi Başkanlı̆̆ı, 2015, http://www.gap.gov.tr/gapsunum-sayfa-144.html, http://www.gap.gov.tr/gap-ta-son-durum-sayfa-32.html, (erişim 4 Haziran 2017).

22 'Güneydoğu Anadolu Projesi Son Durum', 2016, http://yayin.gap.gov.tr/2015-gap-son-durumyayin-...

23 D.P. Forsythe, 'Water and Politics in the Tigris-Euphrates Basin: Hope for Negative Learning?', Water Security in the Middle East: Essays in Scientific and Social Cooperation, J.A. Cahan (ed.), Anthem Press, 2017, s. 169.

24 'Harp Zamanında Sivillerin Korunmasına iliş̧kin Cenevre Sözleşmesi', 12 Ağustos 1949, https://ihldatabases.icrc.org/ihl/385ec082b509e76c41256739003e636d/6756482d86146898c125641e00 4aa3c5, (erişim 3 Haziran 2017).

2512 Ağustos 1949 tarihli Cenevre Sözleşmelerine el uluslararası olmayan silahlı çatışma mağdurlarının korunmasına ilişkin. 8 Haziran 1977.

26 Forsythe, Water and Politics in the Tigris-Euphrates Basin, 2017.

27 'Convention on the Law of the Non-Navigational Uses of International Watercourses', Birleşmiş Milletler, 21 Mayıs 1997, https://treaties.un.org/pages/ViewDetails.aspx?src=TREATY\&mtdsg no=XXVII-12\&chapter=27\&clang= en, (erişim 2 Haziran 2017). 
yeri olmadığını, işbu mekanizmanın devletler arasında eşitsizlik yarattı̆ını ifade etmiştir. ${ }^{28}$ Ayrıca, gelecekte oluşabilecek bir takım anlaşmazlıkları öngörerek bunların çözümü için belirli devletleri kayırıc zorunlu kurallar belirlemenin bir çerçeve anlaşması için uygun olmadığını ve taslak anlaşmanın suyolu devletlerinin kendi topraklarında bulunan uluslararası suyolları üzerindeki egemenliğine hiçbir atıfta bulunmadığına da dikkati çekmiştir. Son olarak Büyükelçi Çelem, bu Sözleşmenin, "önemli hasara yol açmama” yükümlülüğünü öncelikli olarak hakkaniyet ve nısfete uygun ve makul kullanım prensibi üzerine kurması gerektiğini belirtmiştir. ${ }^{29}$

Uluslararası Adalet Divanı Statüsü'nün 38. (1) maddesine göre uluslararası hukukun en temel kaynaklarından birincisi sözleşmeler, ikincisi ise örfi hukuk, diğer ismiyle teamül hukukudur..$^{30}$ Anlaşmaların imza ve onay sürecini müteakip yürürlük kazanması söz konusu olduğundan dahil olacak devletlerin açık rıza beyanı gerekmektedir. Öte yandan, irade beyanı örfi hukukun geçerlilik kazanma sürecinde lüzumlu bir unsur olmadığından küresel (en azından bölgesel) yeknesak uygulama, örfi hukukun oluşması için kâfi görülmektedir. 1997 BM Su Yollarının Kullanımı Sözleşmesinin henüz örfi hukukun bir parçası olmadığı kabul edilmektedir. ${ }^{31}$ Dolayısıyla, 2014 yılında yürürlüğe giren 1997 Sözleşmesi Türkiye için bağlayıcı değildir.

Öte yandan, Türkiye'nin AB ile 2005 yılında başlamış olan adaylık müzakereleri açısından bakıldığında su sorununa yaklaşım farklılı̆ı̆ ortaya çıkmaktadır. Türkiye Fırat ve Dicle'nin sularını kıyıdaşlarla birlikte ve dış tarafların müdahalesi olmadan "iki nehir, tek havza" çerçevesinde ele almayı benimsemektedir. Öte yandan, 2000/60/EC Su Çerçevesi Yönetmeliğini kabul etmiş olan AB, 1992 Helsinki Sözleşmesi'ne taraftır ve kıyıdaşların su sorunlarının çözümünde önce müzakere, sonra Uluslararası Adalet Divanı'nın hakemliği yöntemlerine gidilmesini benimsemiştir. ${ }^{32}$ Dolayısıyla, üyelik müzakere süreci devam ettiği ve $A B$ müktesebat yürürlüğe konulduğu takdirde Türkiye'nin mevcut yaklaşımını terk etmesi ve bu zamana kadar vermeyi kabul ettiğinden çok daha fazla suyu aşağı kıyıdaşlarına bırakması gerekebilecektir. ${ }^{33}$

\section{UYUŞMAZLIK ÇÖZÜMÜ PERSPEKTIFINDEN SU SORUNUNUN DEĞiŞEN YAPISI}

Fırat-Dicle sorununun analizinde uyuşmazlık çözümü (UÇ) yaklaşımı önemli araçlar sunmaktadır. Bir araştırma alanı olarak UÇ çatş̧maları daha iyi anlamaya, şiddeti azaltmaya ve siyasi süreçlerle çıkar farklııklarını gidermeye yönelik fikir, teori ve yöntemleri içer-

28 D.Ö. Dolunay, BM Uluslararası Su Yollarının Ulaşım Dışı Kullanımı Hukukuna İlişkin Sözleşmenin Türkçe Çevirisi, iÜHFM, c. 54, 1997, sy. 4.

29 'Birleşmiş Milletler Genel Kurulu Basın Açıklaması, GA/9248', 21 Mayıs 1997, http://www. internationalwaterlaw.org/documents/intldocs/convention press.html, (erişim 2 Haziran 2017).

30 'Statute of the International Court of Justice', http://legal.un.org/avl/pdf/ha/sicj/icj_statute_e.pdf, (erişim 3 Haziran 2017).

31 A. Schwabach, 'United Nations Convention on the Law of Non-Navigational Uses of International Watercourses, Customary International Law, and the Interests of Developing Upper Riparians', Texas International Law Journal, c. 33, sy. 2, 1998, s. 257-280.

32 C. Akkaya, et al., Avrupa Birliği Su Çerçeve Direktifi ve Türkiye'de Uygulanabilirliği, TMMOB Su Politikaları Kongresi sunumu, Ankara, 2006.

33 Wouters, P., 'The Legal Response to International Water Scarcity and Water Conflicts: The UN Watercourses Convention and Beyond', Allocating and Managing Water for a Sustainable Future: Lessons from Around the World, Yaz konferansı, 11-14 Haziran, 2002. H. Elver, 'Turkey's Rivers of Dispute', Middle East Report, 2010, sy. 40. 
mektedir. ${ }^{34}$ Çatışma sistemlerini etkileyen yapısal ve algısal etkenlere odaklanan UÇ bu yönüyle Barış Çalışmaları alanından ayrılmaktadır. ${ }^{35}$

UÇ alanında en fazla referans verilen teoriler arasında gelen insan gereksinimleri teorisi (IGT) Maslow'un gereksinim hiyerarşisi teorisiyle benzerlikler göstermektedir. ${ }^{36}$ iGT'ye $^{\prime}$ göre güvenlik, grup aidiyeti, kendini gerçekleştirme ve adalet duygusu gibi temel gereksinimler giderilmedikleri takdirde uyuşmazlığa, hatta sıcak çatışmaya yol açabilirler, dolayısıyla pazarlık konusu yapılmamalıdır. ${ }^{37}$ Göreli yoksunluk teorisine göre ise çatışmaların temelinde bir grubun hak ettiğini düşündüğüyle elde edebildiği arasındaki (özellikle başka gruplarla karşılaştrıldığında) uçurumun büyüklüğü yatmaktadır. ${ }^{38}$ Uyuşmazlıkların ortaya çıkmasında kaynakların kıtlığı, tarafların çatı̧macı zihniyeti, birbirlerinin göreceli güçleri hakkında gerçekçi bilgilere sahip olmamaları ve karşılıklı güvensizlik gibi özel etkenler sayılmaktadır. ${ }^{39}$ Bu bağlamda, şiddet illaki silahlı çatışma şeklinde değil, grupların en temel gereksinimlerini karşılamalarının yapısal olarak engellenmesi şeklinde zuhur edebilir. ${ }^{40}$

Diğer bir görüşe göre, bir uyuşmazlığın çözülebilmesi için gereken koşullar arasında firsat (örneğin, yeterli zaman), kapasite (müzakere becerileri, maddi kaynaklar) ve tarafların rızası bulunmaktadır. ${ }^{41}$ UÇ yaklaşımıyla çatışmaların temel sebepleri incelenirken özellikle üçüncü tarafların arabuluculuk ve uzlaştırma (conciliation, İngilizce) gibi katkı potansiyelleri değerlendirilmektedir. Bu çerçevede, Irak, Suriye ve Türkiye arasında 50 yılı aşkın süredir devam etmekte olan su sorunu zengin bir inceleme imkanı sağlamaktadır.

Irak, Suriye ve Türkiye arasındaki su sorununda 1960'lardan "Arap Baharı"na kadar geçen dönemde birincil taraflar üç kıyıdaş ülkeyle sınırlı kalmıştır. Fırat, Dicle ve Asi nehirleri üzerindeki barajların aşağı kıyıdaşların rızası olmadan yapılması ve kullanıma açılması sorunu tetikleyen sebeplerden birisidir. Ancak, bölgede suyun nüfusa ve üretim (tarım, enerji) ihtiyacına kıyasla kıt bir kaynak olmasının yanı sıra taraflar arasından geçmişten gelen ve jeopolitik tehditlerden beslenen güvensizliklerin bulunması sorunun ana sebepleri arasındadır. Örneğin, Keban ve Tabka barajlarının yapımına başlanıldığı Soğuk Savaş döneminde Türkiye, ABD ile işbirliği yapmaktayken SSCB, Suriye ve Irak'taki BAAS rejimlerine yoğun ekonomik ve askeri yardım sağlamışttr. ${ }^{42}$ Karşıt kamplarda yer alan tarafların arasında Hatay gibi başka uyuşmazlıkların bulunması, yukarı kıyıdaşların baraj yaparak suyu kontrol etme niyetleri konusundaki endişeleri

34 J. Bercovitch, et al., The SAGE Handbook of Conflict Resolution, Thousand Oaks, CA: Sage Publications, 2009, s. 1.

35 N. Beriker, 'The Conflict Resolution Field: Reflections on Multiple Realities, Challenges, and Geographical Divides 2015', Brown Journal of World Affairs, 2015, c. XXI, sy. II.

36 A.H. Maslow, 'A Theory of Human Motivation', Psychological Review, ç. 50, sy. 4, 1943, s. 370-96.

37 J. Burton (ed.), 'Introduction', Conflict: Human Needs Theory, Londra: Palgrave Macmillan 1990, s. 1-4.

38 T.R. Gurr, Why Men Rebel, Princeton, NJ: Center of International Studies, Princeton UP, 1970.

39 D.G. Pruitt ve S.H. Kim, Social Conflict: Escalation, Stalemate, and Settlement, New York: McGraw-Hill Higher Education, 2004.

40 J. Galtung, 'A Structural Theory of Imperialism', Journal of Peace Research, ç. 8, sy. 2, 1971, s. 81-117.

41 A.C. Tidwell, Conflict Resolved?: A Critical Assessment of Conflict Resolution, Londra: A\&C Black, 2001.

42 'Soviet Relations with the Baathists in Iraq and Syria', Central Intelligence Agency (CIA), 27 June 1969, https://www.cia.gov/library/readingroom/docs/DOC_0000772106.pdf (erişim 7 Haziran 2017). 
güçlendirmiştir. ${ }^{43}$

Tarihsel çerçevede birincil taraflar arasındaki uyuşmazlık suyun sahipliği ve adil paylaşımı hususlarında yoğunlaşmaktadır. Bu sorunla yakından ilişkili konular arasında Suriye'nin 1998 yılına kadar PKK'yı Türkiye'ye karşı tehdit olarak kullanması ve koordinasyon eksikliği dolayısıyla çevresel sorunlarının aşılamaması sayılabilir. Suriye ve Irak, Türkiye'nin inşa ettiği barajların kendi sularının miktarını ve kalitesini düşürdüğünü, dolayısıyla 1997 Birleşmiş Milletler Uluslararası Su Yollarının Ulaşım Dışı Amaçlarla Kullanımı Sözleşmesi çerçevesinde bir çözümün gerektiğini öne sürmektedir. Buna karşın Türkiye "iki nehir, tek havza" görüşünü savunmakta, Fırat ve Dicle nehirlerinin toplam su potansiyeli üzerinden bir bölüşümün aşağı kıyıdaşlar tarafindan suyun verimli kullanılması ve dış aktörlerin müdahale etmemesi şartlarıyla gerçekleşebileceğini savunmaktadır. ${ }^{44}$

Üç ülke arasındaki su sorunuyla ilişkili ikincil taraflardan birisi PKK'dır. ${ }^{45}$ Suriye ve Türkiye arasında 1998 yılında imzalanan Adana Mutabakatı'na kadar Abdullah Öcalan'ı topraklarında barındıran ve PKK üyelerine kendi kontrolündeki (Asi nehrinin de doğduğu) Bekaa, Lübnan'da üstlenme imkanı sağlayan Suriye, yukarı kıyıdaşının siyasi ve askeri baskısı karşısında terör örgütünü topraklarından çıkarmayı kabul etmek durumunda kalmıştr. ${ }^{46} \mathrm{O}$ tarihe kadar özellikle su sorununda Türkiye'ye karşı DHKP-C, Dev Sol ve TiKKO'nun yanı sıra bir koz olarak kullanılan PKK böylece Suriye'nin nüfuz alanından çıkmış olmakla birlikte, ${ }^{47}$ terör örgütünün barajlarda çalışan personeli kaçırmak ve iş makinelerini yakmak dahil GAP'ın inşasına yönelik saldırıları 2010'lu yıllarda da yoğun olarak devam etmiştir. ${ }^{48}$

Türkiye'nin NATO'da asker sayısı bakımından ikinci büyük orduya sahip olmasının yanı sıra Fırat ve Dicle nehirlerinde yukarı kıyıdaş konumunda bulunması Suriye ve Irak'a karşı fiziki olarak daha güçlü kabul edilmesine yol açmaktadır. ${ }^{49}$ Nitekim aşağı kıyıdaş Irak 1973 yılında Suriye'yi askeri olarak tehdit etmişken Suriye kendi yukarı kıyıdaşı Türkiye'yi direkt olarak karşısına almak yerine PKK gibi terör örgütlerini kullanmayı tercih etmiştir. Yine 1990 yılında Türkiye Atatürk Barajı́nı doldurmak için önceden bilgi vermek suretiyle suyun akışını kestiğinde Suriye ve Irak diplomatik yolu tercih etmiş ve Arap Birliği'nden destek talep etmişlerdir. Arap Birliği nota vermek suretiyle Türkiye'nin karşısında tavır almış, ama Türkiye tutumunda bir değişikliğe gitmemiştir. ${ }^{50}$

43 B. Aras ve H. Köni, 'Turkish-Syrian Relations Revisited', Arab Studies Quarterly, c. 24, sy. 4, 2002, s. 47 60.

44 'Türkiye'nin Su Politikası', T.C. Dışişleri Bakanlığı, 2017, http://www.mfa.gov.tr/turkiye_nin-...

45 Birincil taraf (kıyıdaş) olmamakla birlikte, PKK özellikle baraj inşaatlarına yönelik terör eylemleri ve 1998 yılına kadar Suriye tarafindan desteklenmesi sebepleriyle ikincil taraf olarak kabul edilebilir.

46 A.Ö. Pehlivanoğlu, Ortadoğu ve Türkiye, İstanbul: Kastaş, 2004.

47 G.E. Gruen, 'Turkish Waters: Source of Regional Conflict or Catalyst for Peace?', Water, Air, and Soil Pollution, c. 123, 2000, s. 565-579.

48 'GAP Yatırımlarına Terör Engeli', Anadolu Ajansı, 16 Temmuz 2015, http://aa.com.tr/tr/pg/fotogaleri/gap-yatirimlarina-teror-engeli/0, (erişim 6 Haziran 2017).

49 M. Yetim, 'Governing International Rivers of the Middle East', World Affairs, c. 166, sy. 2, 2003, s. 81-94.

50 Pehlivanoğlu, Ortadoğu ve Türkiye, 2004. Allan, 'The Middle East Water Question', 2001. Zehir, Ortadoğu'da Su Medeniyetlerinden Su Savaşlarına, 2003. 


\section{Şekil 2: Irak ve Suriye Haritası, Ocak 2017}

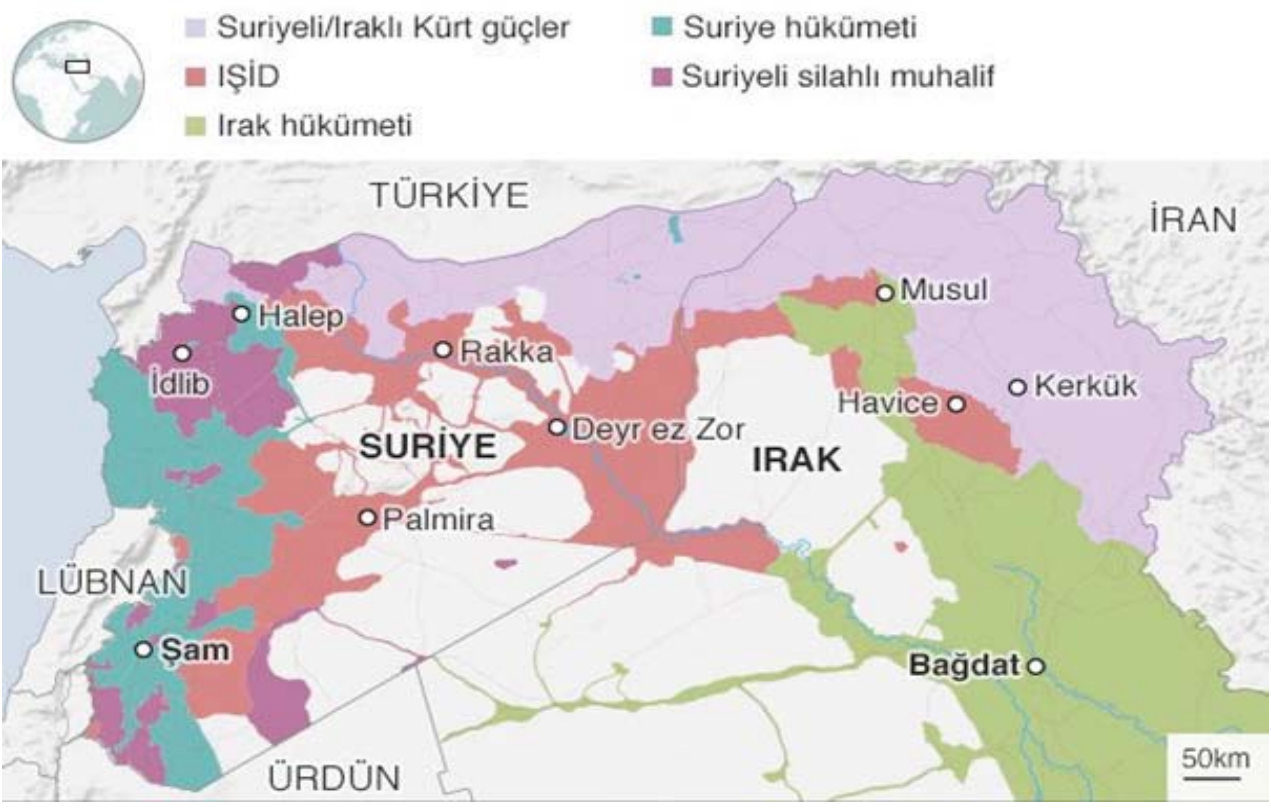

Kaynak: IHS Conflict Monitor, Ocak 2017.51

Üçüncü taraflar arasında komşu devletler öne çıkmaktadır. Örneğin, uyuşmazlığın sıcak bir çatışmaya dönüşmemesinde 1975 yılında Suudi Arabistan ve SSCB’nin, 1998 yılında ise Mısır ve İran devletlerinin arabuluculuğu önemli rol oynamıştır. ${ }^{52}$ Ancak, Arap Birliği zaman zaman Türkiye karşısında tavır alarak arabuluculuk potansiyelini kısıtlamıştır. Erginlik teorisine göre, çatışan tarafların tümüne zarar veren bir çıkmaza girildiğinde uyuşmazlık çözümü için koşullar olgunlaşmış demektir. ${ }^{53}$ Tarafların söz konusu çıkmazın idrakine varmalarında geçmişteki çatışmacı yöntemlerin başarısızlığa uğramasının ve devam ettirilmeleri için gerekli maddi ve toplumsal desteğin kalmamasının etkisi bulunmaktadır. Bununla birlikte, tek bir tarafin dahi çıkmazın farkında olmasının diğer taraflar çözüm konusunda iyimserse yeterli olacağı notunu düşülmektedir. ${ }^{54}$ Bu noktadan hareketle, Suriye ve Türkiye arasında 1998 Adana Mutabakat ile başlayan yakınlaşma döneminin nihai bir anlaşmaya varmada tarihi bir firsat oluşturduğu öne sürülmüş, ancak Türkiye'nin avantajlı konumunu sürdürme beklentisi dolayısıyla uyuşmazlık çözümü koşullarının sağlanmadığı ileri sürülmüştür. ${ }^{55}$

Yukarıda verilen arka plandan hareketle, makalemiz su sorununda yapısal bir değişimin gerçekleşmekte olduğunun altını çizmektedir. Şöyle ki, “Arap Baharı”na kadar üç kıyıdaş devletin birincil taraf olduğu ve suyun insan hayatını tehdit edecek bir silah olarak kulla-

51 IHS Conflict Monitor, Ocak 2017, https://www.ihs.com/products/conflictmonitor.html, (erişim 7 Haziran 2017).

52 Swain, Managing Water Conflict, 2004. Pehlivanoğlu, Ortadoğu ve Türkiye, 2004.

53 I. W. Zartman, "The Timing of Peace İnitiatives: Hurting Stalemate and Ripe Moments", Contemporary Peacemaking: Conflict, Violence and Peace Processes, John Darby ve Roger MacGinty (eds.), New York: Palgrave Macmillan 2003, s. 19-29.

54 D. G. Pruitt ve Sung Hee Kim, Social Conflict: Escalation, Stalemate, and Settlement, New York: McGrawHill Higher Education, 2004.

55 M. Bayar, The Syrian-Turkish Water Conflict in the Rapprochement Period, Saarbrucken, Germany: VDM Verlag 2010, s. 1-99. 
nılmadığı bu uyuşmazlıkta Daeş/IŞiD'in ortaya çıkmasıyla birlikte hem taraf sayısı, hem de kullanılan taktikler değişmiştir. ${ }^{56}$ Adı geçen terör örgütünün önce Irak, sonra da Suriye'deki hedefleri arasında su kaynakları ve barajlar öne çıkmaktadır. Özellikle Dicle nehri üzerindeki Musul barajının ve Samara regülatörünün 2014 yılında Daeş/IşiD tarafindan ele geçirilmesi taraf sayısını artırmıştır. Benzer şekilde, Fırat nehrinin Suriye'den geçen kısmının Tişrin, Rakka ve Deyr ez Zor dahil büyük ölçüde Daeş/IŞiD’in eline geçmesi Esad rejimi için su ve hidroenerji kaynakları açısından kritik kayıplar olmuştur. ${ }^{57}$

Her ne kadar bazı tahminlerin aksine Ortadoğu devletleri arasında su savaşları (henüz) çıkmamışsa da, suyun bölgemizdeki iç savaşlarda ölümcül bir silah olarak kullanılmaya başlandığı ve savaşların niteliğini değiştirdiği görülmektedir. ${ }^{58}$ Örneğin, Daeş/IŞiD Nisan 2014'de Felluce barajının suyunu yönlendirerek çevresindeki Irak ordusu askerlerinin ölümüne sebebiyet vermiş, ülkenin güneyindeki birçok şehrin elektriksiz kalmasına, sel sebebiyle çok sayıda yerleşim yeri ile tarım arazisinin yok olmasına ve binlerce sivilin göçe zorlanmasına yol açmıştır. Ocak 2017'de ise fiili başkenti Rakka'ya 45 km mesafe bulunan Tabka barajının üç türbinini birden açarak aşağı bölgesi Deyr ez Zor'da aşırı sele yol açmıştır. ${ }^{59}$ Buna karşın Esad rejiminin de Halep kuşatması sırasında benzer taktikleri kullandığı tespit edilmiştir. ${ }^{60}$

Daeş/IŞiD 2014 yıında ele geçirdiği Tabka Barajı çevresini Mayıs 2017'de ABD destekli Suriye Demokratik Güçleri'nin saldırısı karşısında terk etmiştir. ${ }^{61}$ Öte yandan, örgüt Musul Barajını sadece 11 gün süreyle elinde tutabilmiş olmasına karşın teknik personelin çoğunluğu kaçttğı ve tamir yapılamadığı için barajın güvenliğine yönelik riskler sürmektedir. ${ }^{62}$

Su sorunundaki diğer bir önemli husus, Kuzey Irak'taki otonom Kürt bölgesinin bağımsızlığını ilan etmesi durumunda birincil taraf sayısının daha da artacağıdır. Halihazırda Dicle nehrinin Irak sınırları içinde kalan bir bölümünü kontrol eden Irak Kürt Bölgesel Yönetimi'nin (IKBY) savaşın sonucuna ve Musul şehrinin kiminde elinde kalacağına bağlı olarak nehir boyunca sınırlarını genişletme potansiyeli bulunmaktadır. Müzakere teorisinden hareketle su sorununu çok daha karmaşık hale getirebilecek bu ihtimal, ${ }^{63}$ makalenin yazıldığı sırada IKBY

56 Burada "taraf" olmaktan kastedilen yasal veya uluslararası anlamda tanınmak değil, uyuşmazlığa konu nehirlerin bir kısım coğrafyasında fiili kontrol sahibi olmaktır.

57 'Water Supply Key to Outcome of Conflicts in Iraq and Syria, Experts Warn', The Guardian, 2 Temmuz 2014, https://www.theguardian.com/environment/2014/jul/02/water-key-conflict-iraq-syria-isis, (erişim 7 Haziran 2017).

58 S. Eker, 'Savaş Olgusunun Dönüşümü: Yeni Savaşlar ve Suriye Krizi Örneği', Türkiye Ortadoğu Çalışmaları Dergisi, c. 2, sy. 1, 2015, s. 31-66.

59 'Former Tabqa Dam Engineer: 'We Could See an Immediate Humanitarian Crisis of Historic Proportions', 26 Ocak 2017, http://syriadirect.org/news/former-tabqa-dam-engineer-\%E2\%80\%98we-could-seean-immediate-humanitarian-crisis-of-historic-proportions\%E2\%80\%99/, (erişim 9 Haziran 2017).

60 S. Kılıç, 'IŞiD, IKBY ve Fırat-Dicle Havzasında Yeni Hidropolitik Düzen', ORSAM Bölgesel Gelişmeler Değerlendirmesi, Temmuz 2014, s. 6. 'Water Supply Key to Outcome of Conflicts in Iraq and Syria, Experts Warn', The Guardian, 2 Temmuz 2014, https://www.theguardian.com/environment/2014/ jul/02/water-key-conflict...

61 'Dikkatle Ele Alınız! Tabka Barajı Trajedisi', ORSAM, 2017, http://orsam.org.tr/orsam/DPAnaliz/12740, (erişim 4 Haziran 2017). 'U.S.-Backed Syria Militias Say Tabqa, Dam Captured from Islamic State', Reuters, 10 Mayıs 2017, http://www.reuters.com/article/us-mideast-crisis-syria-tabqaidUSKBN1862E4 $4_{L}$ (erişim 4 Haziran 2017).

62 Kılıç, 'IŞiD, IKBY ve Fırat-Dicle Havzasında Yeni Hidropolitik Düzen', 2014. “'Musul Barajı her an yıkılabilir", BBC, 29 Şubat 2016, http://www.bbc.com/turkce/haberler/2016/02/160229 musul baraji, (erişim 4 Haziran 2017).

63 Bayar, The Syrian-Turkish Water Conflict in the Rapprochement Period, 2010. 
Başkanı Mesut Barzani'nin Kuzey Irak Kürtleri için bağımsız devletini ilan etme zamanının geldiğini açıklamasıyla güçlenmiştir. ${ }^{64}$ Bütün bu gelişmelere ek olarak, Kuzey Suriye'de, Fırat nehri boyunca, ABD ve Rusya'nın korumasında bir PYD-YPG bölgesi ortaya çıkmaktadır. Bu gelişme, Daeş/IŞiD'in halen kontrol ettiği topraklar göz önüne alındığında Suriye'nin toprak bütünlügü üzerinde, bu ülkeyi Fırat ve Dicle üzerinde bir taraf olmaktan çıkartabilecek derecede belirsizliğe yol açmaktadır. Son olarak, PYD-YPG ile PKK arasındaki Türkiye'nin işaret ettiği organik bağlar su sorununun geleceğini çözümsüz bir noktaya sürüklemektedir.

\section{SONUÇ}

Irak, Suriye ve Türkiye arasında 50 yılı aşkın bir süredir Fırat ve Dicle nehirlerinin statüsü ve kullanımı üzerinden devam etmekte olan su sorunu tarihi gelişimi boyunca trrmanma ve yatışma dönemleri görmüştür. Özellikle yukarı kıyıdaşların barajlarını doldurmaları sırasında aşağı kıyıdaşların sözlü, hatta askeri tehditlerinin görüldüğü bu uyuşmazlıkta su insan hayatını tehdit edecek bir silah olarak kullanılmamış ve üçüncü tarafların da katkısıyla sıcak çatışma önlenmiştir. Öte yandan, Suriye ve Türkiye arasında 2000'li yıllarda başlayıp Suriye iç savaşıyla son bulan yakınlaşma döneminde dahi nihai bir anlaşmaya varılamamış ve Türkiye, diğer iki kıyıdaşın aksine, 1997 Birleşmiş Milletler Uluslararası Su Yollarının Ulaşım Dışı Amaçlarla Kullanımı Sözleşmesine taraf olmamıştır. Türkiye'nin bu Sözleşmeye karşı çıkmasının sebepleri arasında yukarı kıyıdaşların geliştirecekleri baraj yapımı ve diğer projelerde aşağı kıyıdaşların önceden bilgilendirilmesi ve onaylarının alınması zorunluluklarının yanı sıra suyun kullanımında aşağı kıyıdaşlara (tespiti oldukça güç olan) "önemli zarar vermeme" prensibi gelmektedir.

Suyun tek başına (henüz) bir savaş sebebi olmamakla birlikte Ortadoğu'daki iç savaşlarda ölümcül bir silaha dönüşmüş olduğu ortaya çıkmaktadır. "Arap Baharı" sonrası dönemde Daeş/IŞiD ve PYD-YPG gibi devlet dışı aktörlerin Fırat ve Dicle nehirleri boyunca stratejik toprak parçalarını ele geçirmeleri su sorununda yapısal bir değişime yol açmaya başlamıştır. Daeş/IŞiD'in barajları bir silah olarak kullanması, ABD'nin siyasi ve askeri olarak desteklediği PYD-YPG'nin kuzey Suriye'de özerklik ilan etmesi ve Irak Kürt Bölgesel Yönetimi'nin bağımsızlığa yönelik referandum yapacağını duyurması, uyuşmazlığın yeni bir tırmanma dönemine girmesi ihtimalini artırmaktadır.

Irak ve Suriye'deki iç çatışmalar bittiği takdirde nasıl bir haritayla karşı karşıya kalınacağı bugünden kesin olarak bilinememekle birlikte, Fırat-Dicle nehirleri boyunca bir veya birkaç oluşumun bağımsızıı ilan etmesi ve bunların bazı devletler tarafindan (örneğin, İsrail) resmen tanınması olasılık dışı değildir. Ancak, bu oluşumların Irak'ın ve/veya Suriye'nin toprak bütünlüğünü ihlal etmesi sebebiyle mevcut kıyıdaşlar (Irak, Suriye, Türkiye) tarafindan tanınmasına, söz konusu devletlerin bugüne kadarki dış politikaları göz önüne alındığında, ihtimal verilmemektedir. Bu senaryonun gerçekleşmesi durumunda, Fırat ve Dicle nehirleri boyunca fiili ancak meşru olmayan kıyıdaş(lar) ortaya çıkacak ve su sorunu tarihindeki en büyük çıkmaza girecektir. Artan nüfus, kuraklık ve diğer yapısal-siyasi sebeplerden dolayı sınıraşan suların kullanımında işbirliğinin acil ve öncelikli nitelik kazanmakta olduğu bu dönemde, mevcut kıyıdaş devletlerin başta toprak bütünlükleri olmak üzere ortak çıkarları etrafinda bir araya gelmeleri, söz konusu sorunların çözülmesi ve tehditlerin önlenmesi açısından zorunlu görülmektedir.

64 'Barzani: Kürtler için Bağımsızlık Zamanı Geldi', NTV, 2 Mayıs 2017, http://www.ntv.com.tr/dunya/ barzani-kurtler-icin-bagimsizlik-zamani-geldi,XNEScENVjU6-gWKdLIQveQ, (erişim 3 Haziran 2017). 


\section{KAYNAKÇA}

Akbaş, Z., 'Türkiye'nin Fırat ve Dicle Sınıraşan Sularından Kaynaklanan Güvenlik Sorunu ve Çatışma Riski', Bilig, c. Kış, sy. 72, 2015, s. 93-116.

Akkaya, C., et al., Avrupa Birliği Su Çerçeve Direktifi ve Türkiye'de Uygulanabilirliği, TMMOB Su Politikaları Kongresi sunumu, Ankara, 2006.

Al Jabbari, M., et al., 'Rivers of Babylon: Iraq's Water Crisis - And What Turkey Should Do', Foreign Affairs, 23 August 2015. Allan, J.A., 'The Middle East Water Question: Hydropolitics and the Global Economy', Londra, New York: I.B. Tauris, 2001. Aras, B. ve H. Köni, 'Turkish-Syrian Relations Revisited,' Arab Studies Quarterly, c. 24, sy. 4, 2002, s. 47-60.

Bayar, M., The Syrian-Turkish Water Conflict in the Rapprochement Period, Saarbrucken, Germany: VDM Verlag, 2010. Bercovitch, J., et al., The SAGE Handbook of Conflict Resolution, Thousand Oaks, CA: Sage Publications, 2009.

Beriker, N., 'The Conflict Resolution Field: Reflections on Multiple Realities, Challenges, and Geographical Divides 2015', Brown Journal of World Affairs, c. XXI, sy. II, 2015.

Birleşmiş Milletler Gıda ve Tarım Organizasyonu, Towards a Water and Food Secure Future: Critical Perspectives for Policy-makers, Roma, Marsilya: World Water Council, 2015.

Burton, J. (ed.), 'Introduction', Conflict: Human Needs Theory, Londra: Palgrave Macmillan UK 1990, s. 1-4.

Dolunay, D.Ö., 'BM Uluslararası Su Yollarının Ulaşım Dışı Kullanımı Hukukuna illişkin Sözleşmenin Türkçe Çevirisi', iÜHFM, C. 54,1997 , sy. 4.

Eker, S., 'Savaş Olgusunun Dönüşümü: Yeni Savaşlar ve Suriye Krizi Örneği', Türkiye Ortadoğu Çalışmaları Dergisi, c. 2, sy. 1, 2015, s. 31-66.

Elver, H., 'Turkey's Rivers of Dispute', Middle East Report, 2010, sy. 40.

Forsythe, D.P., 'Water and Politics in the Tigris-Euphrates Basin: Hope for Negative Learning?', Water Security in the Middle East: Essays in Scientific and Social Cooperation, Jean A. Cahan (ed.), Anthem Press, 2017, s. 169.

Galtung, J., 'A Structural Theory of Imperialism', Journal of Peace Research, c. 8, sy. 2, 1971, s. 81-117.

Gruen, G.E., 'Turkish Waters: Source of Regional Conflict or Catalyst for Peace?' Water, Air, and Soil Pollution, c. 123, 2000, s. 565-579.

Gurr, T.R., Why Men Rebel, Princeton, NJ: Center of International Studies, Princeton UP, 1970.

Homer-Dixon, T.F., 'On the Threshold: Environmental Changes as Causes of Acute Conflict', International Security, c. 16, sy. 2, 1991, s. 76-116.

Jongerden, J.P., 'Dams and Politics in Turkey: Utilizing Water, Developing Conflict', Middle East Policy, c. 17, sy. 1, 2010, S. 137 - 143.

Kılıç, S., 'IŞiD, IKBY ve Fırat-Dicle Havzasında Yeni Hidropolitik Düzen', ORSAM Bölgesel Gelişmeler Değerlendirmesi, Temmuz 2014, s. 6.

Kıran, A., Ortadogu'da Su: Bir Çatışma ya da Uzlaşma Alanı, Istanbul: Kitap Yayinevi, 2005.

Kibaroğlu, A. ve I.H.O. Ünver, 'An Institutional Framework for Facilitating Cooperation in the Euphrates-Tigris River Basin', International Negotiation, c. 5, 2000, s. 311-330.

Kibaroğlu, A., et al., A Comprehensive Look to the Water Resource Policies of Turkey. TMMOB Su Politikaları Kongresi sunumu, Ankara, 2006.

Maslow, A.H., 'A Theory of Human Motivation', Psychological Review, ç. 50, sy. 4, 1943, s. 370-96.

O'Hanlon, M., 'Coming Conflicts: Interstate War in the New Millenium', Harvard International Review, Yaz, 2001, s. 42-46. Pehlivanoğlu, A.Ö., Ortadoğu ve Türkiye, İstanbul: Kastaş, 2004.

Pruitt, D.G., ve S.H. Kim, Social conflict: Escalation, stalemate, and settlement. New York: McGraw-Hill Higher Education, 2004. Schwabach, A., 'United Nations Convention on the Law of Non-Navigational Uses of International Watercourses, Customary International Law, and the Interests of Developing Upper Riparians', Texas International Law Journal, c. 33, sy. 2, 1998, s. 257-280.

Swain, A., Managing Water Conflict: Asia, Africa and the Middle East, Londra, New York: Routledge, 2004.

Tidwell, A.C., Conflict Resolved?: A Critical Assessment of Conflict Resolution, Londra: A\&C Black, 2001.

United Nations Economic and Social Commission for Western Asia, Inventory of Shared Water Resources in Western Asia, New York: United Nations 2013.

Wouters, P., 'The Legal Response to International Water Scarcity and Water Conflicts: The UN Watercourses Convention and Beyond', Allocating and Managing Water for a Sustainable Future: Lessons from Around the World, Yaz konferansı, 11-14 Haziran, 2002.

Yenigün, C., 'Conflict Resolution for the Middle East: Sectarian Rapprochement', Türkiye Ortadoğu Çalışmaları Dergisi, c. 3, sy. 2, 2016, s. 13-27. 
Yetim, M., 'Governing International Rivers of the Middle East', World Affairs, c. 166, sy. 2, 2003, s. 81-94.

Yoffe, S., et al., 'Geography of International Water Conflict and Cooperation: Data Sets and Applications', Water Resources Research, c. 40, 2004, s. 1-12.

Zartman, I. W., 'The Timing of Peace İitiatives: Hurting Stalemate and Ripe Moments', Contemporary Peacemaking: Conflict, Violence and Peace Processes, John Darby ve Roger MacGinty (eds.), New York: Palgrave Macmillan 2003, s. 19-29.

Zehir, C., Ortadoğu'da Su Medeniyetlerinden Su Savaşlarına, Istanbul: Su Vakfi, 2003.

\section{INTERNET KAYNAKLARI}

'Barzani: Kürtler için Bağımsızlık Zamanı Geldi', NTV, 2 Mayıs 2017, http://www.ntv.com.tr/dunya/barzani-kurtler-icinbagimsizlik-zamani-geldi,XNEScENVjU6-gWKdLIQveQ (erişim 3 Haziran 2017).

'Birleşmiş Milletler Genel Kurulu Basın Açıklaması, GA/9248', 21 Mayıs 1997, http://www.internationalwaterlaw.org/ documents/intldocs/convention_press.html (erişim 2 Haziran 2017).

'Convention on the Law of the Non-Navigational Uses of International Watercourses', Birleşmiş Milletler, 21 Mayıs 1997, https://treaties.un.org/pages/ViewDetails.aspx?src=TREATY\&mtdsg_no=XXVII-12\&_chapter=27\&clang=_en (erişim 2 Haziran 2017).

'Dikkatle Ele Alınız! Tabka Barajı Trajedisi', ORSAM, 2017, http://orsam.org.tr/orsam/DPAnaliz/12740 (erişim 4 Haziran 2017).

Kırkıcı, D.D., 'Sınıraşan Sular Bağlamında Türkiye, Suriye ve Irak iliş̧kileri', Uzmanlık Tezi, T.C. Orman ve Su İşleri Bakanlığı, Ankara 2014, http://suyonetimi.ormansu.gov.tr/Libraries/su/DUYGU_DO\%C4\%9EU_KIRKICI-UZMANLIK_ TEZ\%C4\%BO__nihai.sflb.ashx (erişim 4 Haziran 2017).

'Former Tabqa Dam Engineer: 'We Could See an İmmediate Humanitarian Crisis of Historic Proportions', 26 Ocak 2017, http://syriadirect.org/news/former-tabqa-dam-engineer-\%E2\%80\%98we-could-see-an-immediatehumanitarian-crisis-of-historic-proportions\%E2\%80\%99/ (erişim 9 Haziran 2017).

'GAP Yatırımlarına Terör Engeli', Anadolu Ajansı, 16 Temmuz 2015, http://aa.com.tr/tr/pg/foto-galeri/gap-yatirimlarinateror-engeli/0 (erişim 6 Haziran 2017).

'GAP Sunum”, "GAP'ta Son Durum', GAP Bölge Kalkınma İdaresi Başkanlığı, 2015, http://www.gap.gov.tr/gap-sunumsayfa-144.html, http://www.gap.gov.tr/gap-ta-son-durum-sayfa-32.html (erişim 4 Haziran 2017).

'Güneydoğu Anadolu Projesi Son Durum', 2016, http://yayin.gap.gov.tr/2015-gap-son-durum-yayin-ef1457f5b1.html (erişim 4 Haziran 2017).

'Harp Zamanında Sivillerin Korunmasına ilişskin Cenevre Sözleşmesi', 12 Ağustos 1949, https://ihl-databases.icrc.org/ih I/385ec082b509e76c41256739003e636d/6756482d86146898c125641e004aa3c5 (erişim 3 Haziran 2017).

IHS Conflict Monitor, Ocak 2017, https://www.ihs.com/products/conflictmonitor.html, (erişim 7 Haziran 2017).

'International Water Event Database, International Freshwater Treaties Database', 12.05.2017, The Transboundary Freshwater Dispute Database, College of Earth, Ocean, and Atmospheric Sciences, Oregon State University, http://www.transboundarywaters.orst.edu (erişim 6 Haziran 2017).

“Musul Barajı her an yıkılabilir", BBC, 29 Şubat 2016, http://www.bbc.com/turkce/haberler/2016/02/160229_musul_ baraji (erişim 4 Haziran 2017).

'Soviet Relations with the Baathists in Iraq and Syria', Central Intelligence Agency (CIA), 27 June 1969, https://www.cia. gov/library/readingroom/docs/DOC_0000772106.pdf (erişim 7 Haziran 2017).

'Statute of the International Court of Justice', http://legal.un.org/avl/pdf/ha/sicj/icj_statute_e.pdf (erişim 3 Haziran 2017).

'Su Hukuku ve Politikaları ìntisas Heyeti "Dicle-Fırat Havzası" Gündemi Ille Toplandı', T.C. Orman ve Su İşleri Bakanlığı, Su Yönetimi Genel Müdürlüğü, 17 Aralık 2015, http://suyonetimi.ormansu.gov.tr/AnaSayfa/ resimliHaber/15-12-17/Su_Hukuku_ve_Politikalar\%C4\%B1_\%C4\%BOhtisas_Heyeti_\%E2\%80\%9CDicleF\%C4\%B1rat_Havzas\%C4\%B1\%E2\%80\%9D_G\%C3\%BCndemi_\%C4\%BOle_Topland\%C4\%B1.aspx?sflang=tr (erişim 4 Haziran 2017).

'Türkiye'nin Su Politikası', T.C. Dışişleri Bakanlığı, 2017, http://www.mfa.gov.tr/turkiye_nin-su-politikasi.tr.mfa (erişim 4 Haziran 2017).

'U.S.-Backed Syria Militias Say Tabqa, Dam Captured from Islamic State', Reuters, 10 Mayıs 2017, http://www.reuters. com/article/us-mideast-crisis-syria-tabqa-idUSKBN1862E4 (erişim 4 Haziran 2017).

'Toprak Su Kaynakları', 2014, http://www.dsi.gov.tr/toprak-ve-su-kaynaklari (erişim 7 Haziran 2017).

'Water Issues between Turkey, Syria and Iraq', Stratejik Araştrmalar Merkezi (SAM), 2012, http://sam.gov.tr/wpcontent/uploads/2012/01/WATER-ISSUES-BETWEEN-TURKEY-SYRIA-AND-IRAQ.pdf (erişim 6 Haziran 2017).

'Water Supply Key to Outcome of Conflicts in Iraq and Syria, Experts Warn', The Guardian, 2 Temmuz 2014, https:// www.theguardian.com/environment/2014/jul/02/water-key-conflict-iraq-syria-isis (erişim 7 Haziran 2017). 